\title{
Effects of Afforestation on Water Resource Variations in the Inner Mongolian Plateau
}

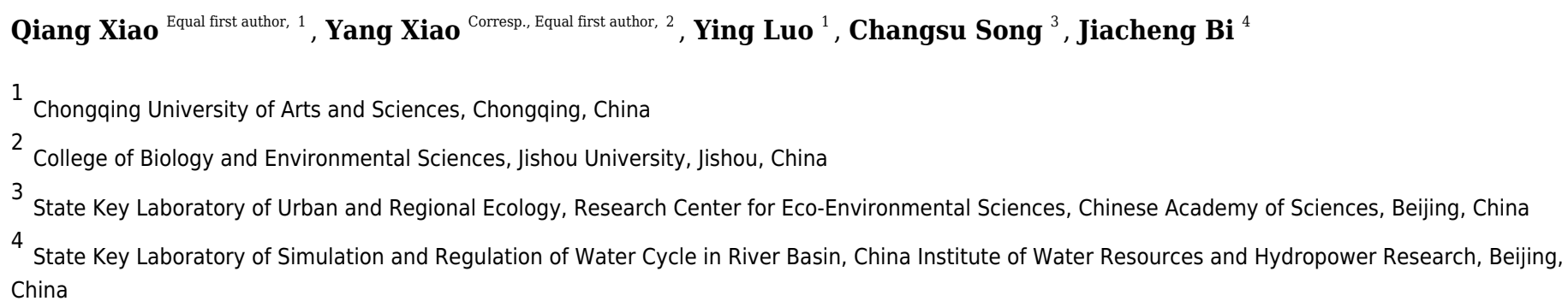

Afforestation is a key approach used to effectively prevent ecosystem degradation, which in itself is a key reason for the obstruction of sustainable societal development. In order to suppress sand and dust storms as a result of ecological environmental degradation in North China, the Government of China has sanctioned the planting of a large number of trees in Inner Mongolia. However, water resources in the Inner Mongolian Plateau are insufficient to sustain this effort because such a large number of trees consume a large amount of water, which also significantly increases evapotranspiration. This study uses spatiotemporal trend analyses and abrupt change analyses to determine the effects of afforestation on water resource variations in the Inner Mongolian Plateau. Results show that even though water resources in Inner Mongolia fluctuate, this resource has generally exhibited a declining trend from 1980 to 2015, corresponding to the NDVI trend. On spatial-temporal scales, water resources decreased significantly in the eastern section of the plateau, especially in the Horqin District and the Hulunbuir Plateau. By contrast, water resources increased as a whole in the western section of the plateau (Alxa Plateau).

Driving analysis results show that water resource variation is mainly due to the contribution of change in precipitation (positive effect), which accounted for $39.35 \%$ of total changes in water resources, followed by the evapotranspiration (negative effect). In other words, afforestation with the primary aim of improving ecosystem has effectually upset the water resource balance of Inner Mongolia Plateau. 
1 Effects of Afforestation on Water Resource Variations in the

2 Inner Mongolian Plateau

3 Qiang Xiao ${ }^{1}$, Yang $\mathrm{Xiao}^{2,3}$, Ying Luo ${ }^{1}$, Changsu Song ${ }^{3}$,Jiacheng $\mathrm{Bi}^{4}$

61 Chongqing University of Arts and Sciences, Chongqing, 402160, China;

72 College of Biology and Environmental Sciences, Jishou University, Jishou 416000, China;

83 State Key Laboratory of Urban and Regional Ecology, Research Center for Eco-Environmental Sciences, Chinese

9 Academy of Sciences, Beijing 100085, China;

104 State Key Laboratory of Simulation and Regulation of Water Cycle in River Basin, China Institute of Water

11 Resources and Hydropower Research, Beijing 100038, China

Corresponding Author:

Yang $\mathrm{Xiao}^{2,3}$

120 Renmin South Road, Jishou City, Hunan Province 416000, China

16 Email address: yangxiao84@hotmail.com

Abstract:

Afforestation is a key approach used to effectively prevent ecosystem degradation, which in itself is a key reason for the obstruction of sustainable societal development. In order to suppress sand and dust storms as a result of ecological environmental degradation in North China, the Government of China has sanctioned the planting of a large number of trees in Inner Mongolia. However, water resources in the Inner Mongolian Plateau are insufficient to sustain this effort because such a large number of trees consume a large amount of water, which also significantly increases evapotranspiration. This study uses spatiotemporal trend analyses and abrupt change analyses to determine the effects of afforestation on water resource variations in the Inner Mongolian Plateau. Results show that even though water resources in Inner Mongolia fluctuate, this resource has generally exhibited a declining trend from 1980 to 2015, corresponding to the NDVI trend. On spatial-temporal scales, water resources decreased significantly in the eastern section of the plateau, especially in the Horqin District and the Hulunbuir Plateau. By contrast, water resources increased as a whole in the western section of the plateau (Alxa Plateau). Driving analysis results show that water resource variation is mainly due to the contribution of change in precipitation (positive effect), which accounted for $39.35 \%$ of total changes in water resources, followed by the evapotranspiration (negative effect). In other words, afforestation with the primary aim of improving ecosystem has effectually upset the water resource balance of Inner Mongolia Plateau. 


\section{Introduction}

Being part of the Mongolian Plateau located in Eurasia, Inner Mongolia, whose terrain is dominated by plateau and mountainous areas, is an important ecological barrier in North China(Ouyang et al. 2018). In recent years, drought and anthropogenic impacts in the region have intensified sand and dust storms(Cordeiro et al. 2018). As a result, these particulates have changed the composition of dust clouds, which have affected most of the world to the extent that floating dust from Inner Mongolia can reach the Pacific Coast of North America(Cheng et al. 2006). Some studies have reported that overgrazing in the research area has led to the wilting of grassland and the formation of deserts(Kong et al. 2015, deCastro-Arrazola et al. 2018). In actual fact, the plateau is comprised of some of the most vulnerable ecosystems in the world due to its particular environmental structure, composition, and location. Accordingly, the question of how to develop a new ecological resource management model specific to the region has been of key concern for the Government of China.

Water resources refer to water resources that can be used or may be used. They are an important part of natural resources, have sufficient quantity and appropriate quality, and meet the specific needs of a certain place for a period of time. China is a country with severe drought and water shortage. It is one of the thirteen countries with the poorest per capita water resources in the world. Moreover, the spatial and temporal distribution of water resources is very uneven. To mitigate or reverse the environmental deterioration of the region while protecting its local water resources, the Government of China launched a massive tree planting program in the Inner Mongolian Plateau that from 1955 to 2015 has exceeded $36000 \mathrm{~km}^{2}$ (Fan et al. 2016). In spite of the fact that vegetation cover on the Inner Mongolian Plateau has increased in recent years, the impact of ecological restoration policies in this region progress has been made in research. (Cao \&Zhang 2015).

Many countries are currently facing issues related to increasing water scarcity (Alton 2018). It is estimated that available water per capita in China is only approximately one-fourth of the world average, and water resource per capita in arid areas of Inner Mongolia is only $355 \mathrm{~m}^{3}$. In recent years, a large number of people in Shanxi Province, Inner Mongolia, and parts of Beijing and Tianjin cities and Hebei Province in North China has suffered from the destruction of the ecological environment and the scarcity of water resources resulting from conditions of almost continuous drought. Given that the Inner Mongolian Plateau is the primary ecological barrier of Inner Mongolia and the Beijing-Tianjin-Hebei region, for those who rely on this barrier, the methods used by the Government of China to protect the ecological environment and water resources on the plateau will have a significant impact on the effectiveness of the ecological barrier of the region(Miao et al. 2015, Escobar-Flores et al. 2018). Many studies have reported that China's large-scale water resource protection plans and water transport projects will significantly affect the ecological environment and available water resources in the Inner Mongolian Plateau and the Beijing-Tianjin-Hebei region. Northeast Asia is also subject to similar potential ecological impacts resulting from these plans and projects.

Inner Mongolia and the Beijing-Tianjin-Hebei region are the territories most affected by the relationship among variations in water resources, sand and dust storms, and afforestation(Tagesson et al. 2018). A number of water resource shortage studies in North China reported that this large-scale afforestation program will severely affect the amount of available water resources in the region(Cao et al. 2016). In addition, the effects of climate change on the amount of precipitation and vegetation cover in the Inner Mongolian Plateau will aggravate the impact of sand and dust storms in this region. A regions' available water resource typically leads to water competition among various species within an ecosystem, as well as competition between natural 
ecosystems and human requirements. Researchers have predicted that river systems in China's Mongolian Plateau will effectively dry up due to the overexploitation of water resources of some rivers(Feng et al. 2017). In certain areas of the Inner Mongolian Plateau, the excessive use of groundwater has led to a serious decline in groundwater levels, causing a series of ecological problems, including large-scale vegetation mortality, an increase in sand and dust storms, and overall environmental degradation. Furthermore, biodiversity in the western region of the Mongolian Plateau will decline as the climate becomes progressively dryer and desertified areas expand(Yang et al. 2019a).

Although we are dependent upon ecosystem resources, our understanding of ecosystem processes is very limited(Wilson \&Norman 2018). Therefore, we need to better understand such processes and integrate this knowledge into the management of the ecological environment as well as formulate better policies and plans to manage it. The purpose of this paper is as follows.: 1. The most important science-based problems that require urgent study in the Inner Mongolian Plateau are how to manage relationships among water resources, sand and dust storms, and afforestation. 2. how to overall variation trends of water resources and vegetation on the Mongolian Plateau, Causes of water resource variations on the Mongolia Plateau 3. how to evaluate the impact of afforestation on water resource variation to promote the effective utilization of water resources and reduce the impact of sand and dust storms.

\section{Materials and Methods}

\subsection{Study area}

Inner Mongolia is located in the arid and semi-arid climate region. The average annual temperature is between $-5 \sim 10{ }^{\circ} \mathrm{C}$, and the average annual precipitation is between $35 \sim 530 \mathrm{~mm}$, Under the comprehensive influence of temperature and water conditions, vegetation zones mainly show the spatial differentiation characteristics in the near meridional direction. From east to west, they are successively forest, forest grassland belt, typical grassland belt, desert grassland belt and desert belt. The dominant land type in the study region is grassland (Fig. 1), which includes steppe and sparsely distributed grass, comprising of approximately $73.2 \%$ of the plateau, mostly distributed throughout the central and eastern sections. With the increase of population and the development of economy, the disturbance degree of human activities on the grassland gradually enhance, resulting in a certain degree of ecological degradation in this region. In recent years, the Government of China has implemented several ecological protection and construction programs to alleviate grassland degradation in Inner Mongolia (Fig. 2), however, these programs could also significantly affect the eco-hydrological process of grassland ecosystems. The ecological protection and construction planning programs mainly include the Three-North Shelter Forest Program, the conversion from farmland to forest and grassland, sandy land control, and ecological relocation projectets.

$<$ Figure 1 here please $>$

$<$ Figure 2 here please $>$

\subsection{Data sources}

In order to determine afforested area within the Inner Mongolian Plateau, we used afforestation data across Inner Mongolia from 1980 to 2015 . We obtained afforestation data from annually published China forestry statistical yearbooks from 1980 to 2015 (State Forestry Agency of the People's Republic of China 
115 (1980 to 2015)). All cartographic data were converted to the same coordinate system (Albers equal-area conic

116

117

118

119

120

121

122

123

124

125

126

127

128

129

130

131

132

133

134

135

136

137

138

139

140

141

142

143

144

145

146

147

148

149

150

151

152 projection) and the same spatial resolution $(1 \mathrm{~km})$.

We obtained Chinese ecosystem data between 1980 and 2015 (the study period) from the Data Sharing Infrastructure of Earth System Science at the Chinese Academy of Science (http://www.geodata.cn). These data were produced at a resolution of $1 \mathrm{~km}$, using visual interpretations of Landsat (MSS/TM/OLI) images with an average overall accuracy greater than $94 \%$.

We obtained meteorological between 1980 and 2015 from the National Metrological Information Center of the China Meteorological Administration (http://data.cma.cn). Digital elevation model (DEM) data originated from the Shuttle Radar Topography Mission (SRTM), with a resolution of 90 m. Administrative divisions were provided by the Satellite Environment Center, the China Ministry of Environmental Protection (MEP). Lastly, we obtained the continental Global Inventory Modeling and Mapping Studies (GIMMS) normalized difference vegetation index (NDVI, NDVI=(NIR-R)/ (NIR+R), NIR is near-infrared band, $\mathrm{R}$ is red band) dataset, with a spatial resolution of $8 \mathrm{~km}$ and covering a period from 1982 to 2015, from the Ecological Forecasting Lab at the NASA Ames Research Center (https://ecocast.arc.nasa.gov).

\subsection{Methods}

(1) Water resource quantification:

Considering the special climatic and geographical environment in Inner Mongolia, there is a close interaction between climate factors, hydrocycle, and evaportranspiration. Budyko (1974) proposed a theoretical framework to describe the effect of precipitation and evapotranspiration on water storage based, which is an effective method to study the hydrological response to climate change. To quantitatively analyze water resources, we applied a water balance equation based on the Budyko model to the hydro series (from 1980 to 2015).

For this analysis, we do not consider the interaction between surface and groundwater on horizontal direction, due to the interaction usually happens in the vertical direction (Xiao \& Xiao 2019a).

The water balance of a catchment can be described as follows (Xiao \& Xiao 2019a):

$$
Q=P-E T_{a}-\Delta S
$$

where $Q$ is the water storage $(\mathrm{mm})$ as a proxy of the water resource; $P$ and $E T_{a}$ represent precipitation (mm) and actual evapotranspiration $(\mathrm{mm})$; and $\Delta S$ represents a change in catchment water storage (mm), which is usually assumed to be zero over a long period of time(Xiao \& Ouyang, 2019b)..

(2) Evapotranspiration factor $(E T)$ :

Following an assumption similar to that made by Budyko (1974), actual evapotranspiration can be estimated as follows(Shen et al. 2015):

$$
E T=\frac{P \times E T_{p}}{\left(P^{n}+E T_{p}^{n}\right)^{1 / n}}
$$

where $E T$ is the actual evapotranspiration $(\mathrm{mm}) ; n$ is the model controlling parameter that determines the shape of the Budyko curve, which mainly represents the integrated effects of catchment land-cover characteristics on the water balance. $E T_{p}$ is the potential evapotranspiration, and it can be estimated by the Priestley-Taylor (PT) equation (Priestley \& Taylor 1972) as follows:

$$
E T_{p}=\alpha \times \frac{\Delta}{\Delta+\gamma} \times\left(R_{n}-G\right)
$$




$$
\Delta=\frac{4098 \times\left(0.6108 \exp \left(\frac{17.27 T}{T+237.3}\right)\right)}{(T+237.3)^{2}}
$$

$$
\gamma=0.665 \times 10^{-3} \times 101.3 \times\left(\frac{293-0.0065 H}{293}\right)^{5.26}
$$

where $\alpha$ is the PT coefficient of 1.26 for open water and saturated land (Priestley and Taylor 1972); $\Delta$ is the slope of the saturated vapor pressure curve $\left(\mathrm{kPa}^{\circ} \mathrm{C}^{-1}\right) ; \gamma$ is the psychrometric constant $\left(\mathrm{kPa}^{\circ} \mathrm{C}^{-1}\right) ; R_{n}$ is the net radiation absorbed at the surface in $\mathrm{MJ} \mathrm{m}^{-2}$, which can be estimated using calibrated radiation in the FAO 56PM model; $G$ is the downward-directed soil heat flux in $\mathrm{MJ} \mathrm{m}^{-2}$, where $G=0.26 R_{n} ; T$ is the mean air temperature $\left({ }^{\circ} \mathrm{C}\right) ; H$ is elevation above sea level $(\mathrm{m})$.

(3) Spatiotemporal analyses:

The 'Spatial Analyst' tools in ArcGIS 10.3 were employed to reveal the spatial characteristics of water resources in different regions. To detect the variation in trends of water resources during the study period (1980-2015), a least squares linear regression model which is a commonly used method in trend analysis of variation, can be used to obtain the trend of every pixel change by fitting a linear equation of water resource variables as a function of time (year). The trend value was calculated by programming in Interactive Data Language (IDL) 4.8 (Harris Corporation, Melbourne, FL, USA).

(4) Abrupt change analyses:

We mainly conducted analysis of abrupt changes in water resources using the Mann-Kendall (MK) test (Xiao \& Ouyang, 2019b). We used this method on the premise that the positive sequence curve UF $_{\mathrm{k}}$ crosses the critical ratio reliability line; therefore, if the positive sequence (UF) and the inverse sequence (UB, generated with the reverse data series of UF) have only one obvious crossing point located between the reliability lines, this denotes the catastrophe point and is statistically significant. On the other hand, if the crossing point is located outside the reliability line or there are several obvious crossing points between the lines, a definite catastrophe point cannot be established. In this latter case, we used the MK test on different lengths of sequences separately on the basis of a moving t-test technique. If a catastrophe point was still shown in these different sequences, we could then confirm that this point was the definite catastrophe point (Pettitt,1979). The Mann-Kendall trend test can be described as follows:

For a time series $\mathrm{X}=\{\mathrm{x} 1, \mathrm{x} 2, \ldots, \mathrm{xn}\}$, the test statistic is given by

$$
\mathrm{S}_{k}=\sum_{\mathrm{i}=1}^{\mathrm{i}=k} n_{i}
$$

The statistics time series $\mathrm{S}_{\mathrm{k}}$ is from $i=1,2, \ldots, \mathrm{k}$, for any dual value $\left(\mathrm{x}_{\mathrm{i}}, \mathrm{x}_{\mathrm{j}}\right)$, if $\mathrm{j}<\mathrm{i}, \mathrm{x}_{\mathrm{i}}>\mathrm{x}_{\mathrm{j}}$, an upward trend is stated, $\mathrm{n}_{\mathrm{i}}$ is the total number of dual values with growth trend.

The expected variance of $\mathrm{S}_{\mathrm{k}}$ is calculated as follow,

$$
\mathrm{E}\left(\mathrm{S}_{\mathrm{k}}\right)=\mathrm{k}(\mathrm{k}-1) / 4, \operatorname{Var}\left(\mathrm{S}_{\mathrm{k}}\right)=\mathrm{k}(\mathrm{k}-1)(2 \mathrm{k}+5) / 72 \text {. }
$$

and the forward trend sequence $\mathrm{UF}_{\mathrm{k}}$ is given as:

$$
U F_{k}=\frac{S_{k}-E\left(S_{k}\right)}{\sqrt{\operatorname{Var}\left(S_{k}\right)}}
$$

\subsection{Validation:}

To verify the reliability of simulated water resources in Inner Mongolia, we validated simulated results 
against observed data, which are available from the China Water Resources Bulletin from 1998 to 2015 (Ministry of Water Resources of the People's Republic of China; 1998-2015).

\section{Results}

\subsection{Overall variation trends of water resources and vegetation on the Mongolian Plateau}

Before the spatio-temporal analyses, we Validate the reliability of simulated water resources in Inner Mongolia, and the simulations agreed well with corresponding estimates (average $r=0.84 ; p<0.001$; Fig. 3). We could therefore confirm that simulated water resources could also be considered reasonable.

$<$ Figure 3 here please $>$

In recent years, water resources in Inner Mongolia have fluctuated but have generally exhibited a declining trend between 1980 and 2015 (a decrease of $0.2 \mathrm{~mm} / \mathrm{yr}$ ). This declining trend is unfavorable to vegetation growth. NDVI exhibited a similar trend. On a continental scale, 1998 generated the maximum water resource and NDVI values (Fig. 4). At the same time, Fig. 4 also provides interannual variations and their influencing factors (such as temperature, evapotranspiration, precipitation, and plantation area) throughout 1980-2015. The decrease in rainfall and the increase in evapotranspiration in the region are not favorable to water resource storage. The characteristic of statistics of the six variables was shown as table 1 .

$<$ Figure 4 here please $>$

$<$ Table1 here please $>$

\subsection{Declining water resources in the Mongolian Plateau:}

On a regional scale, almost the entire Mongolian Plateau has experienced water shortages between 1980 and 2015 (Fig. 5a). As a whole, water resources decreased significantly in the eastern section of the plateau, especially in the Horqin District and the Hulunbuir Plateau. By contrast, water resources increased as a whole in the western section of the plateau (Alxa Plateau). To evaluate long-term changes in water resources, we calculated the turning points of trends using the MK trend test and the Pettitt's test. As shown in Fig. 5b, we identified two distinctly different trends throughout 1980-1998 and 1999-2015.

$<$ Figure 5 here please $>$

\subsection{Causes of water resource variations on the Mongolia Plateau:}

There were obvious relationship among the various driving factors and water resources (Table 2). Our regression results found significant effects for six parameters associated with water resource changes from 1980 to 2015 (Table 3). For parameter value effects on water resources, the highest contribution was increasing precipitation (accounting for $39.35 \%$ of the total water resource changes), followed by increasing evapotranspiration (-24.48\%), increasing DEM (22.72\%), and increasing village density (-7.10).

$<$ Table2 here please $>$

$<$ Table3 here please $>$

\section{Discussion}

\subsection{Temporal pattern of water resource variation}

Results from our study clearly show that water resources in Inner Mongolia fluctuated significantly but generally exhibited a declining trend between 1980 and 2015 (a decrease of $0.2 \mathrm{~mm} / \mathrm{yr}$ ). NDVI exhibited a similar trend(Miao et al. 2016, Shi et al. 2019). These trends are not favorable to vegetation growth. Potential 
causes for these declining trends are that water consumption of artificial vegetation is far higher than that of natural vegetation; thus, the practice of restoring the environment and water resources in the Inner Mongolia Plateau by means of afforestation is likely to further aggravate existing water resource shortages(Liu et al. 2018, Cao et al. 2019).

Fig. 3 also shows interannual variations of influencing factors (such as temperature, evapotranspiration, precipitation, and planting area) from 1980 to 2015. Since 1978, a series of large-scale ecological restoration projects have been implemented in China, including the Three-North Shelter Forest Program, natural forest protection projects, and conversion projects from farmland to forest and grassland to name a few. Greater than $30 \mathrm{yr}$ of practical experience has confirmed that green vegetation cover within the study area has rapidly increased by means of these environmental policies(Lu et al. 2018). However, compared to the natural recovery of abandoned land, afforestation in arid areas has reduced total vegetation cover, increased degraded areas, and aggravated local desertification. The key internal mechanism that causes such water-related problems is as follows, when precipitation is less than evapotranspiration, vegetation (including trees) will be forced to rely on groundwater extraction to survive, leading to the depletion of surface water and a decline in groundwater levels, thereby reducing the availability of water resources for all vegetation(Wu et al. 2017). At the same time, a decrease in rainfall and an increase in evapotranspiration are not favorable to water resource storage.

Our results also showed that this water resource reversal in the Mongolian Plateau is intensifying, namely, that vegetation has begun to further degenerate due to large-scale afforestation initiatives (by an increase of $12.79 \times 103 \mathrm{ha} / \mathrm{yr}$ ) and global climate warming (by an increase of $0.044^{\circ} \mathrm{C} / \mathrm{yr}$ ).

The MK trend test and Pettitt's test showed that there was an abrupt change in water resources around 1998, namely, water resources declined rapidly after 1998. This was mainly due to the fact that precipitation in Inner Mongolia has decreased yearly since 1998 while afforestation area has increased rapidly since that time, which has caused an annual increase in temperature and increased consumption of local water reserves. Along with this decline in water resources, the status of grassland vegetation has also gradually degenerated.

\section{2 spatial pattern of water resources variation}

Our research results clearly found a significant reduction in water resources in the eastern region of the Mongolian Plateau, especially in the Horqin District and the Hulunbuir Plateau. In contrast, there has been an increase in the total amount of water resources in the western region (Alxa Plateau)(Yao et al. 2017). The cause of this duel phenomenon is likely the implementation of ecological construction projects, such as natural forest resource protection initiatives(Liu et al. 2018), the conversion from farmland to forest(Chang et al. 2011), the Three-North Shelter Forest Program(Wang et al. 2007), and compensation for public welfare forests(Yang et al. 2012), which have resulted in increased evapotranspiration and reduced rainfall in the region, while the usual practice of the Government of China is to simply promote a balance between different ecological service policies and practices.

With respect to the current increase in rainfall in the western region of Inner Mongolia, we belie ve this region should primarily be designated grassland. Namely, the protection and improvement of $n$ atural grassland ecosystems should be the key focus of the government, that it should abide by meas ures that combine protection and construction initiatives, and by sponsoring measures suitable to local conditions to further promote the ecological function of grassland and effectively alleviate grassland $\mathrm{d}$ egradation and desertification trends, thereby developing a virtuous cycle (Yang et al.2019b). We sh 
ould also plan livestock feeding according to the availability of grass, promote a balance between grassla nd and livestock, convert grazing land to grassland, establish grassland protection areas, build artificial grassland areas in farming and pastoral farming areas, relocate population density beyond its environm ental bearing capacity, etc., to strengthen the protection of grassland(Fan et al. 2010).

\subsection{Policy implications of water resources management}

Being a public resource, the Government of China should instigate a comprehensive plan of action for water resources on a regional scale to ensure its sustainable utilization and to minimize negative impacts to the ecological environment. Similarly, prior to the implementation of an ecological policy, the Government of China must also take into account environmental factors, such as global climate change, sand and dust storms, as well as other relevant factors(Chavas 2017). Concerning water resource variation on the Inner Mongolian Plateau, we found clear evidence that showed that water scarcity issues in the overall region primarily result from precipitation(Wu et al. 2013). Changes in precipitation have yielded a positive feedback on changes in water resources (a 39.35\% contribution rate), while changes in water resources were primarily a consequence of increased evapotranspiration (a $-24.48 \%$ contribution rate). A potential likely reason behind this is the large number of artificial forests that have been planted in the region in recent decades, resulting in increased evapotranspiration. Furthermore, village density in the Mongolian Plateau has had a negative impact on changes in water resources, which suggests that anthropogenic activities (such as the development of stockbreeding, afforestation, etc.) in recent years have had a significant impact on the region.

\section{Conclusions}

Before we interfere with stable ecosystems, we must keep in mind that our behavior is constrained by ecosystem response mechanisms. This is because ecosystems are complex and are not yet fully understood. Any attempt to restore ecological environments should first be strictly accessed in order to expose possible unforeseen consequences. Whether the goal is to protect nature or to protect our own interests, it is vital that we be prudent in our actions. The results of this study show that no matter what measures are taken, the key point is to protect the dynamic balance among water resources, sand and dust storms, and afforestation in the Inner Mongolian Plateau. To achieve this goal, we need to adopt a holistic way of thinking. For example, we need to carefully judge and weigh the impact of every managerial action on water resources as well as the lives of people and ecosystems that are dependent on them.

Our results show the effects of afforestation on water resource variation in the Inner Mongolian Plateau. Over the last 30 years, vegetation evapotranspiration indices have risen, while large-scale afforestation has also resulted in an increase in total evapotranspiration (when compared to past evapotranspiration in the region), and subsequently the consumption of local water resources. Studies have reported that such degradation is due to the emphasis on short-term behavior and the neglect of ecological impacts. In this study, we determined the existence of a balance among some of the main ecological elements, which demonstrates that the best approach in protecting the ecological environment is to carefully maintain the original state of ecosystems.

\section{Acknowledgements}

We would like to thank Denise Rennis for his help in writing this paper as well as journal editors and anonymous reviewers for their comments on an earlier version of this manuscript. 
305

306

307

308

309

310

311

312

313

314

315

316

317

318

319

320

321

322

323

324

325

326

327

328

329

330

331

332

333

334

335

336

337

338

339

340

341

342

343

344

345

\section{References}

Alton, P B. 2018. Decadal trends in photosynthetic capacity and leaf area index inferred from satellite rem ote sensing for global vegetation types. Agricultural and Forest Meteorology,250,361-375.DIO:10.1016/j.agrfo rmet.2017.11.020

Budyko M I.1974. Climate and life. Academic, New York, USA.

Cao Q, Wu JG, Yu DY, Wang W.2019. The biophysical effects of the vegetation restoration program on regional climate metrics in the Loess Plateau, China. Agricultural and Forest Meteorology,268,169-180.D IO:10.1016/j.agrformet.2019.01.022

Cao SX, Zhang JZ. 2015. Political risks arising from the impacts of large-scale afforestation on water resources of the Tibetan Plateau. Gondwana Research,28,898-903.DIO:10.1016/j.gr.2014.07.002

Cao SX, Zhang JZ, Chen L, Zhao TY.2016. Ecosystem water imbalances created during ecological restor ation by afforestation in China, and lessons for other developing countries. J Environ Manage,183,843-849.

DIO:10.1016/j.jenvman.2016.07.096

Chang RY, Fu BJ, Liu G, Liu S.2011. Soil Carbon Sequestration Potential for "Grain for Green" Project in Loess Plateau, China. Environmental Management,48,1158-1172.DIO:10.1007/s00267-011-9682-8

Chavas JP. 2017. On food security and the economic valuation of food. Food Policy,69,58-67.DIO:10.1016 /j.foodpol.2017.03.008

Cheng H, Wu YQ, Zou XY, Si H, Zhao YZ, Liu DG, Yue, XL.2006. Study of ephemeral gully erosion in a small upland catchment on the Inner-Mongolian Plateau. Soil \& Tillage Research,90,184-193.DIO:10.10 16/j.still.2005.09.006

Cordeiro LP, Hofmann GS, Fonseca C, Oliveria FB.2018. Achilles heel of a powerful invader: restrictio ns on distribution and disappearance of feral pigs from a protected area in Northern Pantanal, Western Bra zil. Peerj,6. DIO:10.7717/peerj.4200

deCastro-Arrazola I, Hortal J, Moretti M, Sanchez-Pinero F.2018. Spatial and temporal variations of ari dity shape dung beetle assemblages towards the Sahara desert. Peerj,6. DIO:10.7717/peerj.5210

Escobar-Flores J G, Lopez-Sanchez CA, Sandoval S, Marquez-Linares MA, Wehenkel C.2018. Predicti ng Pinus monophylla forest cover in the Baja California Desert by remote sensing. Peerj,6. DIO:10.7717/pe erj. 4603

Fan J W, Shao QQ, Liu JY, Wang JB, Harris W, Chen ZQ, Zhong HP, Xu XL, Liu RG. 2010. Ass essment of effects of climate change and grazing activity on grassland yield in the Three Rivers Headwate rs Region of Qinghai-Tibet Plateau, China. Environmental Monitoring and Assessment,170,571-584.DIO:10.1 007/s10661-009-1258-1

Fan J W, Harris W, Zhong HP.2016. Stoichiometry of leaf nitrogen and phosphorus of grasslands of the Inner Mongolian and Qinghai-Tibet Plateaus in relation to climatic variables and vegetation organization lev els. Ecological Research,31,821-829.DIO:10.1007/s11284-016-1392-5

Feng LX, Brown RW, Han BF, Wang ZZ, Luszczak K, Liu B, Zhang ZC, Ji JQ. 2017. Thrusting an $\mathrm{d}$ exhumation of the southern Mongolian Plateau: Joint thermochronological constraints from the Langshan Mountains, western Inner Mongolia, China. Journal of Asian Earth Sciences,144,287-302.DIO:10.1016/j.jseae s.2017.01.001

Kong DX, Miao CY, Borthwick, AGL, Duan QY, Liu H, Sun QH, Ye AZ, Di ZH, Gong, W.2015. E volution of the Yellow River Delta and its relationship with runoff and sediment load from 1983 to 2011. 
Journal of Hydrology,520,157-167.DIO:10.1016/j.jhydrol.2014.09.038

Liu LZ, Yang X, Zhou HK, Liu SS, Zhou L, Li XH, Yang JH, Han XY, Wu JJ. 2018. Evaluating th e utility of solar-induced chlorophyll fluorescence for drought monitoring by comparison with NDVI derive $\mathrm{d}$ from wheat canopy. Science of the Total Environment,625,1208-1217.DIO:10.1016/j.scitotenv.2017.12.268 Liu XF, Liu XH, Shao XM, Songer M, He BS, He XB, Zhu Y.2018. Plant diversity patterns of temper ate forests with logging and restoration practices in northwest China. Ecological Engineering,124,116-122.DI O:10.1016/j.ecoleng.2018.09.017

Lu CX, Zhao TY, Shi XL, Cao SX. 2018. Ecological restoration by afforestation may increase groundwat er depth and create potentially large ecological and water opportunity costs in arid and semiarid China. Jou rnal of Cleaner Production,176,1213-1222.DIO:10.1016/j.jclepro.2016.03.046

Miao CY, Ashouri H, Hsu KL, Sorooshian S, Duan, QY. 2015. Evaluation of the PERSIANN-CDR Dai ly Rainfall Estimates in Capturing the Behavior of Extreme Precipitation Events over China. Journal of Hy drometeorology,16,1387-1396.DIO:10.1175/jhm-d-14-0174.1

Miao CY, Kong DX, Wu JW, Duan QY.2016. Functional degradation of the water-sediment regulation sc heme in the lower Yellow River: Spatial and temporal analyses. Sci Total Environ,551-552,16-22.DIO:10.10 16/j.scitotenv.2016.02.006

Ouyang W Y, Wu YY, Hao ZC, Zhang Q, Bu QW, Gao X.2018. Combined impacts of land use and s oil property changes on soil erosion in a mollisol area under long-term agricultural development. Science o f the Total Environment,613,798-809.DIO:10.1016/j.scitotenv.2017.09.173

Pettitt AN .1979. A non-parametric approach to the change-point problem. Appl Statist, 28, 126-135.

Priestley C H, Taylor R J.1972. On the assessment of surface heat flux and evaporation using large scale parameters. Mon Wea Rev,100,81-92.

Shen RC, Xu M, Li RQ, Zhao FX, Sheng QK.2015. Spatial variability of soil microbial biomass and its relationships with edaphic, vegetational and climatic factors in the Three-River Headwaters region on Qingh ai-Tibetan Plateau. Applied Soil Ecology,95,191-203.DIO:10.1016/j.apsoil.2015.06.011

Shi P Y, Zhang Y, Ren ZP, Yu Y, Li P, Gong JF.2019. Land-use changes and check dams reducing ru noff and sediment yield on the Loess Plateau of China. Science of the Total Environment,664,984-994.DIO:1 0.1016/j.scitotenv.2019.01.430

Tagesson T, Horion S, Nieto H, Fornies VZ, Gonzalez GM, Bulgin CE, Ghent D, Fensholt R.2018. D isaggregation of SMOS soil moisture over West Africa using the Temperature and Vegetation Dryness Inde $x$ based on SEVIRI land surface parameters. Remote Sensing of Environment,206,424-441.DIO:10.1016/j.rse. 2017.12.036

Wang XH, Bennett J, Xie C, Zhang ZT, Liang D.2007. Estimating non-market environmental benefits of the Conversion of Cropland to Forest and Grassland Program: A choice modeling approach. Ecological Eco nomics,63,114-125.DIO:10.1016/j.ecolecon.2006.10.001

Wilson NR, Norman LM. 2018. Analysis of vegetation recovery surrounding a restored wetland using the normalized difference infrared index (NDII) and normalized difference vegetation index (NDVI). Internation al Journal of Remote Sensing,39,3243-3274.DIO:10.1080/01431161.2018.1437297

Wu JW, Miao CY, Zhang XM, Yang TT, Duan QY. 2017. Detecting the quantitative hydrological respo nse to changes in climate and human activities. Science of the Total Environment,586,328-337.DIO:10.1016/ j.scitotenv.2017.02.010 
387 Wu LH, Hui LH, Wang XY, Li JY, Yu JL, Zhao J.2013. Abundance and composition of ammonia-oxid 388 ising bacteria and archaea of a degraded lake wetland, Inner Mongolian Plateau, China. Soil Research,51,55 389 4-560.DIO:10.1071/sr13160

390 Xiao Y, Xiao Q. 2019a. Impact of large-scale tree planting in Yunnan province, China, on the water supp 391 ly balance in Southeast Asia. Environ Monit Assess, 191: 20. DOI 10.1007/s10661-018-7131-3

392 Xiao Y, Ouyang ZY. 2019b. Spatial-temporal Patterns and Driving Forces of Water Retention Service in 393 China. Chinese Geographical Science, 1-12. DOI 10.1007/s11769-018-0984-0

394 Yao J, Mao W, Yang Q, Xu Z. 2017.Annual actual evapotranspiration in inland river catchments of Chin 395 a based on the Budyko framework. Stoch Environ Res Risk Assess,31: 1409-1421. DOI:10.1007/s00477-016 $396-1271-1$.

397 Yang L, Wei W, Chen LD, Mo BR. 2012. Response of deep soil moisture to land use and afforestation 398 in the semi-arid Loess Plateau, China. Journal of Hydrology,475,111-122.DIO:10.1016/j.jhydrol.2012.09.041

399 Yang Y, Wang, L, Wendroth O, Liu B, Cheng C, Huang T, Shi Y. (2019a). Is the laser diffracti 400 on method reliable for soil particle size distribution analysis? An evaluation by sieve-pipette method a 401 nd scanning electron microscopy. Soil Sci. Soc. Am. J. DIO:org/10.2136/sssaj2018.07.0252

402 Yang Y, Jia X, Wendroth O, Liu B, Shi Y, Huang T, Bai X. (2019b). Noise-Assisted multivariate empirical 403 mode decomposition of saturated hydraulic conductivity along a south-north transect across the Loess Plateau 404 of China. Soil Sci. Soc. Am. J. doi: 10.2136/sssaj2018.11.0438. 
Table $\mathbf{1}$ (on next page)

Various driving factors 
2

3 Table1. The description of statistics of the various driving factors and water resources from 1980 to 2015.

\begin{tabular}{cccccc}
\hline & Mean & Maximum & Minimum & Standard error & Coefficient of Variance \\
\hline Water resource & 36.19 & 125.65 & 4.04 & 25.58 & 0.71 \\
NDVI & 299.93 & 417.83 & 229.68 & 42.13 & 0.14 \\
Evapotranspiration & 3.75 & 5.45 & 2.25 & 0.71 & 0.19 \\
Precpitation & 283.83 & 309.81 & 258.77 & 11.08 & 0.04 \\
Temperature & 252.79 & 266.43 & 244.21 & 5.73 & 0.02 \\
Afforestation & 591.67 & 907.39 & 256.52 & 170.56 & 0.29 \\
\hline
\end{tabular}

4

5

6 
Table 2 (on next page)

Correlation analysis 
4 Table2. The correlation analysis on relationship among the various driving factors and water resources.

\begin{tabular}{|c|c|c|c|c|c|c|c|}
\hline & $\begin{array}{l}\text { Water } \\
\text { resource }\end{array}$ & $\begin{array}{l}\text { Precipitatio } \\
\mathrm{n}\end{array}$ & $\begin{array}{l}\text { Temperatur } \\
\text { e }\end{array}$ & $\begin{array}{l}\text { Evapotranspiratio } \\
\mathrm{n}\end{array}$ & $\begin{array}{l}\mathrm{DE} \\
\mathrm{M}\end{array}$ & $\begin{array}{l}\text { Slop } \\
\text { e }\end{array}$ & $\begin{array}{l}\text { Villag } \\
\mathrm{e}\end{array}$ \\
\hline \multicolumn{8}{|l|}{ Water } \\
\hline resource & 1 & & & & & & \\
\hline Precipitation & 0.78 & 1 & & & & & \\
\hline Temperature & 0.04 & 0.21 & 1 & & & & \\
\hline \multicolumn{8}{|l|}{ Evapotranspi } \\
\hline ration & -0.49 & 0.01 & 0.31 & 1 & & & \\
\hline DEM & 0.45 & 0.57 & 0.50 & -0.03 & 1 & & \\
\hline Slope & 0.09 & -0.23 & -0.34 & -0.50 & -0.06 & 1 & \\
\hline Village & -0.14 & -0.01 & 0.04 & 0.20 & -0.03 & 0.10 & 1 \\
\hline
\end{tabular}

5

6 
Table 3 (on next page)

Regression results 
3 Table3. Regression results of relationships between the various driving factors and water resources after 4 normalization. Contributions (\%) represent the proportion of the total change in water resources accounted for 5 by a given driving factor (Standard coefficient/Total absolute value of Standard coefficient).

\begin{tabular}{lcccc}
\hline & $\mathrm{R}^{2}$ & Adjusted $\mathrm{R}^{2}$ & Contribution (\%) & Standard coefficient \\
\hline Precipitation & $0.61^{* *}$ & $0.609^{* *}$ & 39.35 & 0.781 \\
Temperature & 0.001 & -0.001 & 1.81 & 0.036 \\
Evapotranspiration & $0.236^{* *}$ & $0.235^{* *}$ & -24.48 & -0.486 \\
DEM & $0.204^{* *}$ & $0.202^{* *}$ & 22.72 & 0.451 \\
Slope & $0.008^{*}$ & $0.006^{*}$ & 4.53 & 0.090 \\
Village & $0.02^{* *}$ & $0.018^{* *}$ & -7.10 & -0.141 \\
\hline
\end{tabular}

6 Notes: $R^{2}$ is the regression goodness of fit based on the value of each driving factor. Parameters with significant contributions to 7 regressions were identified by repeated measures ANOVA. $* * p<0.01, * p<0.05$. 
Figure $\mathbf{1}$ (on next page)

Location and ecosystem distribution map of China's Inner Mongolian region 


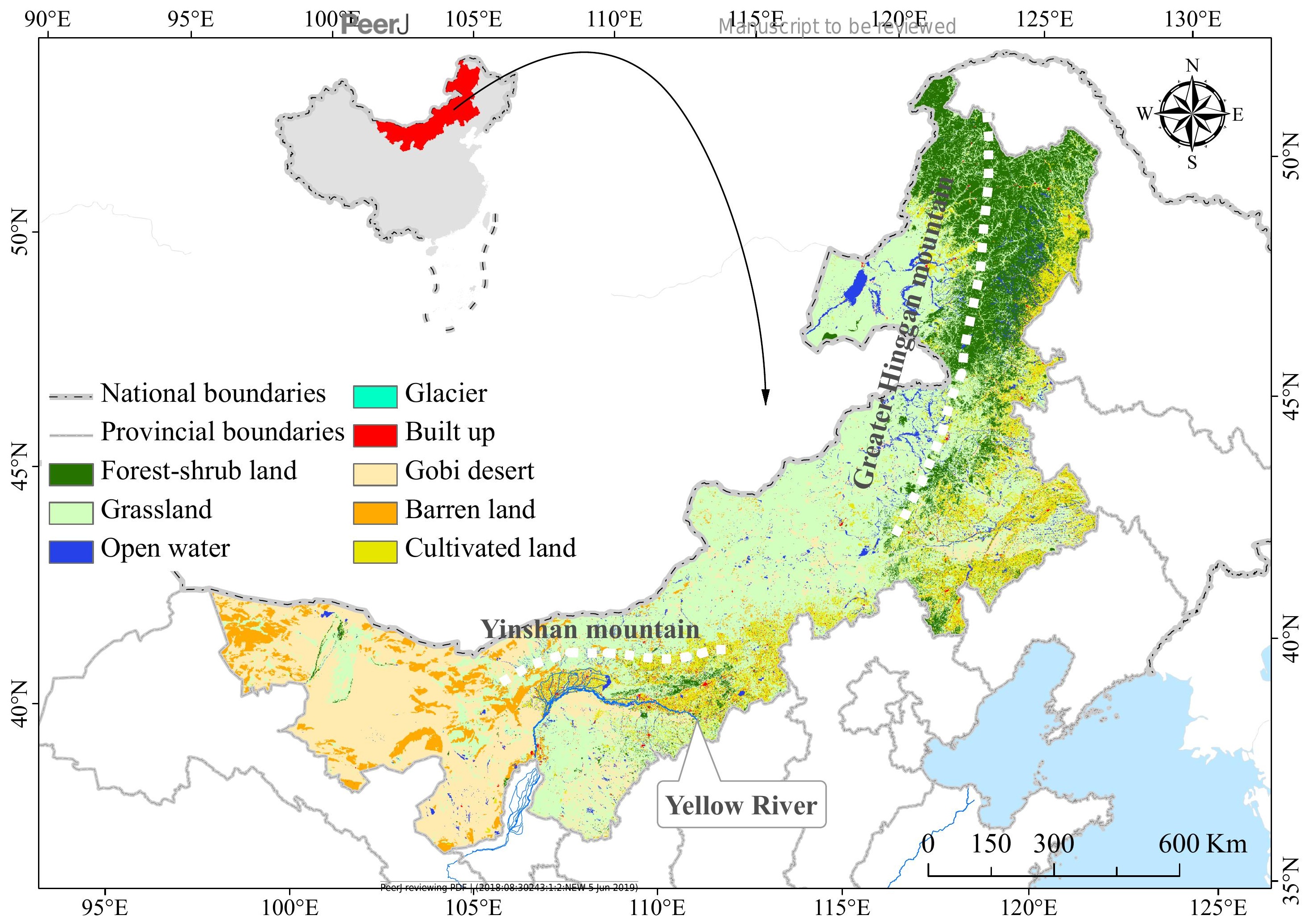




\section{Figure 2}

Typical Area Characteristics of the Research Area

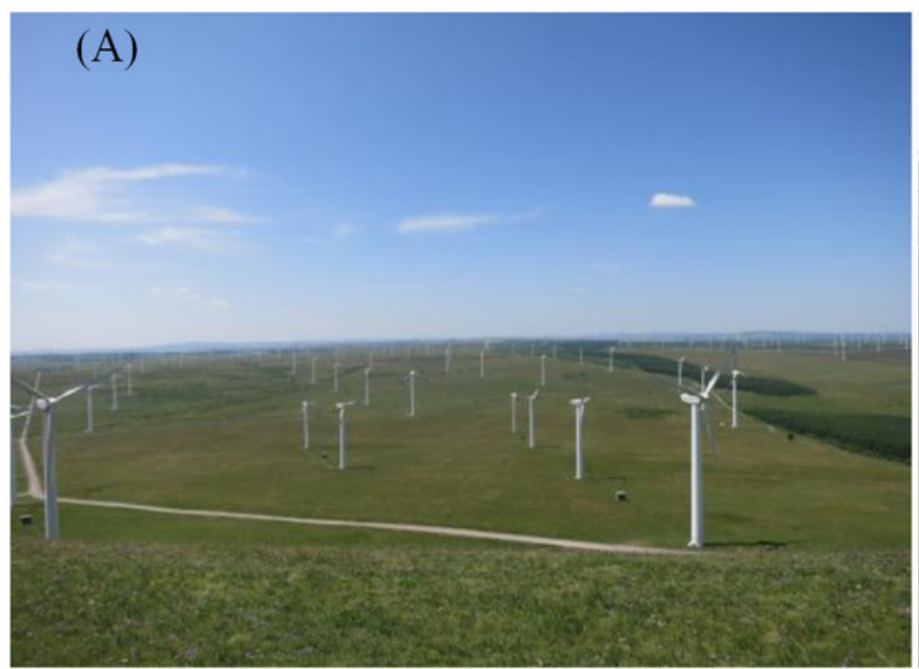

(B)

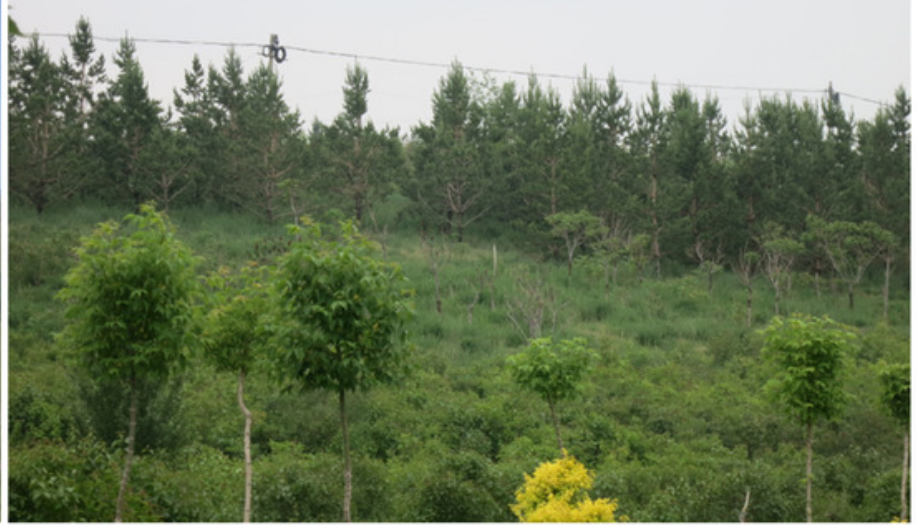


Figure 3

Validation of water resource results from 1998 to 2015

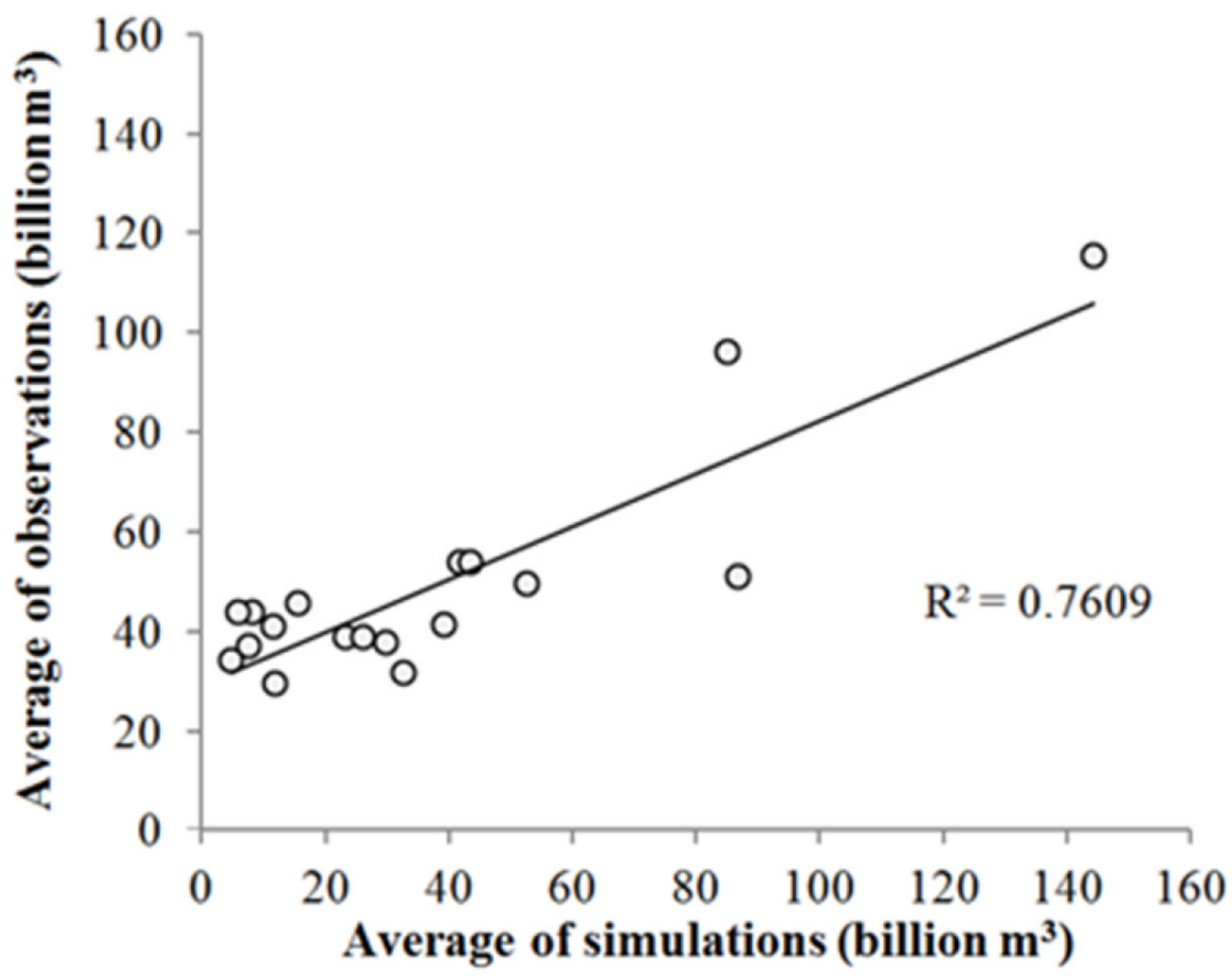


Figure 4

Interannual variations of water resources, NDVI, evapotranspiration, precipitation, and temperature
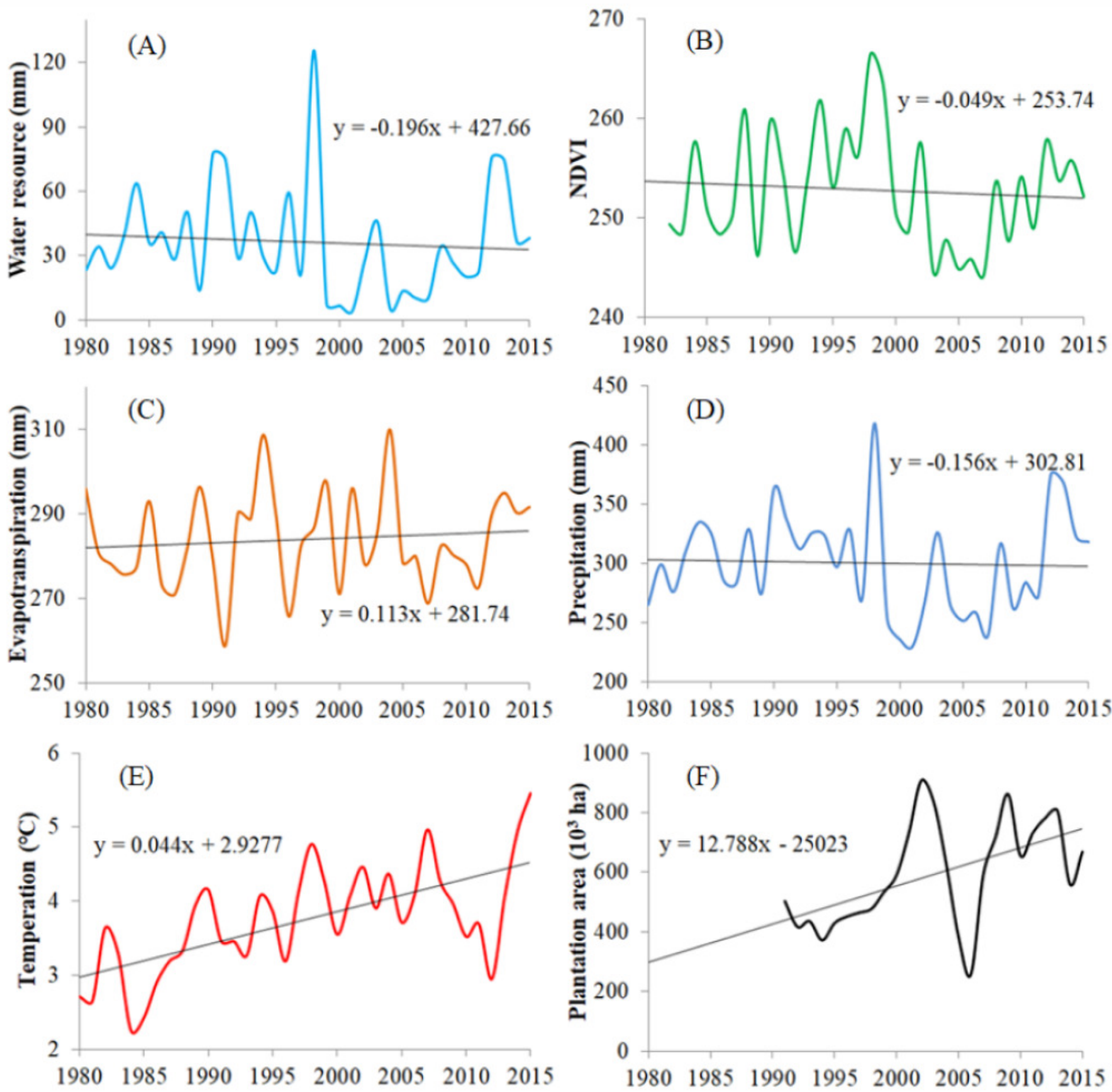
Figure $\mathbf{5}$ (on next page)

Change trends and abrupt change tests of water resources in the Mongolian Plateau 


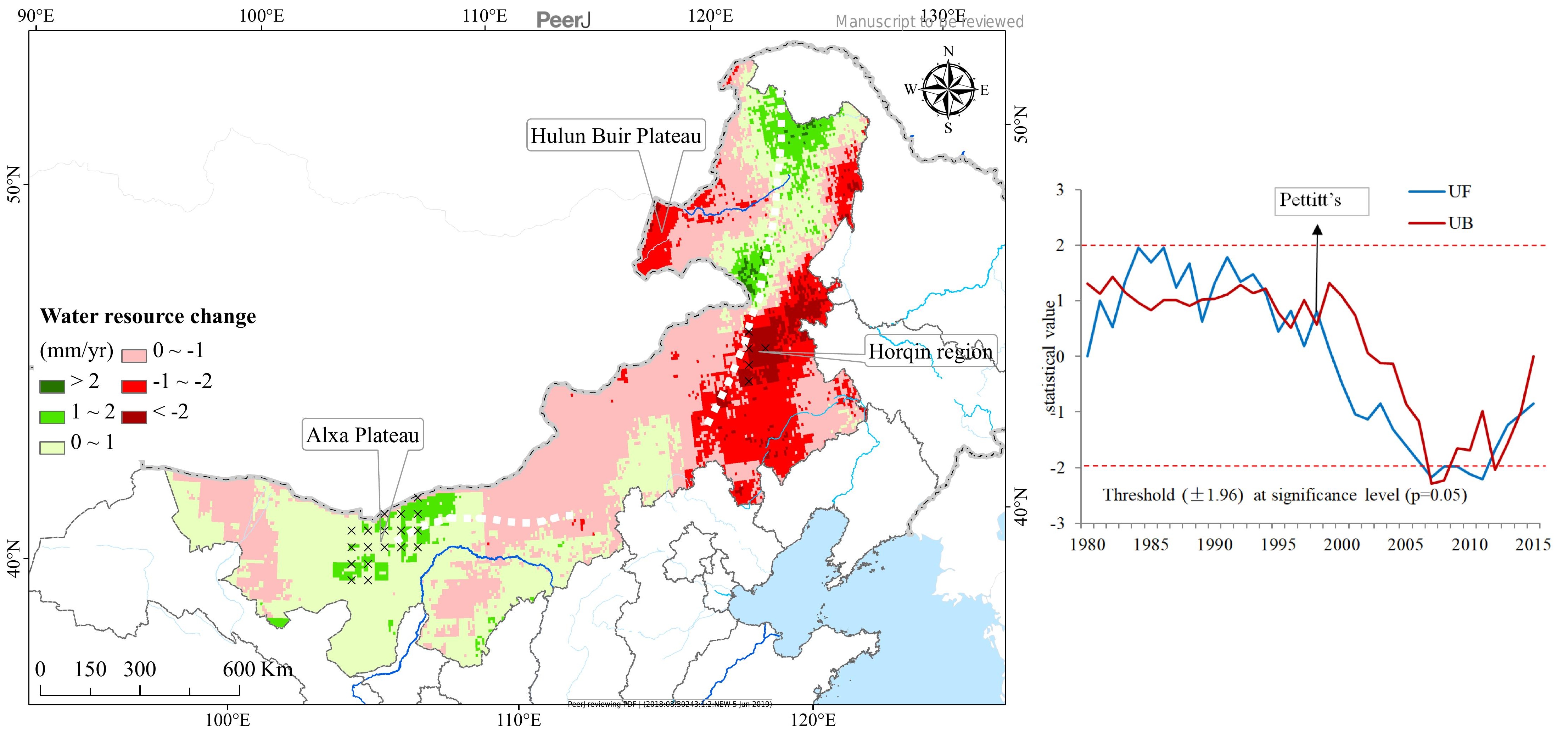

